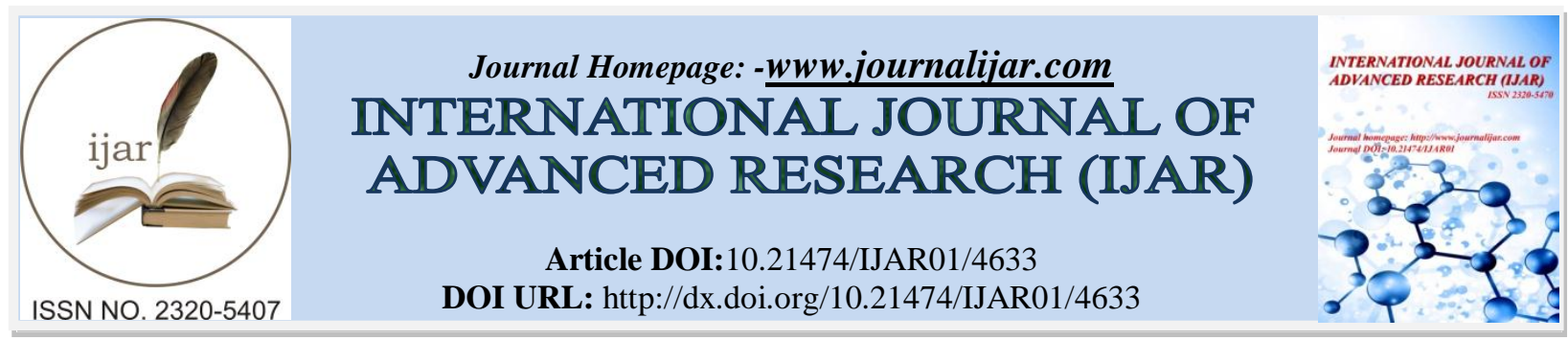

RESEARCH ARTICLE

\title{
Effect of three regimens of prophylactic antibiotics in pregnant women with preterm premature rupture of fetal membranes: A randomised comparative study.
}

\author{
Dr. Geetika Arora, Dr. S. S. Trivedi, Dr. Sharda Patra and Dr. Manisha.
}

\section{Manuscript Info}

Manuscript History

Received: 27 April 2017

Final Accepted: 29 May 2017

Published: June 2017
Abstract

Background: The benefit of prophylactic antibiotic therapy in preterm PROM is well established by several trials however data relating to prophylactic antibiotics in Indian women is limited which might be due to difference in the microbiological flora of the Indian women from the western women. The present work was done with an aim to assess the effect of three different regimens of prophylactic antibiotics in pregnant women with pPROM on maternal and neonatal morbidity and mortality. Methods: Pregnant women with pPROM between 28 to 34 weeks $(n=150)$ were randomised into three equal groups $(n=50)$ of prophylactic antibiotics regimens. Group 1 received Inj Ampicillin 1gm IV 6 hrly for 48 hrs followed by amoxicillin 500mg orally 8 hrly for 5 days. Group 2 received oral erythromycin $250 \mathrm{mg}$ 8hrly for 7 days and Group 3 received Ampicillin 1gm IV 6 hourly + Metronidazole $500 \mathrm{mg}$ IV 8 hourly for $48 \mathrm{hrs}$ followed by amoxicillin 500mg orally 8 hrly for 5 days. The period from rupture of membranes to delivery (Latency) was calculated and the maternal - neonatal outcome was compared between these groups. Results: The latent period between rupture of membranes and delivery was significantly longer in the women who received only Inj Ampicillin (Group 1) and combination of Inj. Ampicillin with metronidazole (Group 3) compared to women who received oral erythromycin $(8.92 \pm 7.12$ and $9.34 \pm 9.17$ days vs. $6.18 \pm 6.11$ days; $\mathrm{p}=0.005$ ). However the difference in the latent period between Ampicillin and Ampicillin with metronidazole group was non-significant $(8.92 \pm 7.12$ vs. $9.34 \pm 9.17 ; \mathrm{p}=0.482)$. The frequency of maternal complications like clinical chorioamnionitis was significantly higher $(6 \%)$ in women who received erythromycin compared to the women who received ampicillin $(0 \%)$ and ampicillin + metronidazole $(0 \%)$, the difference was highly significant $(\mathrm{p}=$ 0.047).Though the difference in the rates of puerperal sepsis, PPH, neonatal sepsis, intraventricular haemorrhages and neonatal mortality was insignificant. Conclusion:The use of prophylactic antibiotic either single ampicillin or in combination ampicillin+ metronidazole in preterm PROM significantly prolongs gestation and appears to decrease maternal morbidity due to chorioamnionitis and hence proved to be more efficacious over erythromycin .

Copy Right, IJAR, 2017,. All rights reserved. 


\section{Introduction:-}

Premature rupture of membranes or prelabour rupture of membranes (PROM) is defined as rupture of fetal membranes in the absence of uterine contractions regardless of gestational age[1,2]. PROM occurring after 37 completed weeks of gestation is known as Term PROM (TPROM) and that occurring before 37 weeks is Preterm PROM (pPROM). The management of pPROM involves a conservative approach with an aim to deliver a healthy mature fetus without jeopardizing maternal health. It includes maternal administration of corticosteroids and prophylactic antibiotics. Several trials of antibiotic therapy have shown prolongation of the latency period, reduction in neonatal morbidity, and decreased incidence of maternal infection. Administration of prophylactic antibiotics in cases of pPROM delays the progression to preterm birth and reduces the neonatal consequences of prematurity and neonatal sepsis such as respiratory distress syndrome, use of surfactant, oxygen therapy, infections including pneumonia and intra ventricular haemorrhages leading to abnormal cerebral ultrasound scan prior to discharge from hospital [3].

Although several trials have shown a beneficial effect of prophylactic antibiotic therapy on maternal -fetal outcome, however the optimal drug or combination of drugs, route of administration, and duration of therapy are yet to be determined [4-21]. Because of the variety of potential pathogens colonizing the vagina (and possibly the amnion after membrane rupture), broad-spectrum antibiotics offer some theoretical advantages over narrow-spectrum agents. A potential pitfall of broad spectrum agents is the emergence of resistant organisms. However data relating to prophylactic antibiotics in pPROM in Indian set up is limited. The microbiological flora of Indian women could have a variation from the western women. No study relating to this has been done so far, hence which antibiotic would be beneficial is still not known. This study was done to assess the effect of three different regimens of prophylactic antibiotics in women with pPROM on maternal and neonatal morbidity and mortality.

\section{Materials and Methods:-}

It was a randomised, prospective study including 150 pregnant women presenting with preterm premature rupture of membranes between 28-34 weeks gestation. These women were recruited from the Casualty of the Department of Obstetrics and Gynaecology, Lady Hardinge Medical College, New Delhi from November 2012 to March 2014. All subjects presenting with pPROM were subjected to thorough history and detailed physical examination as per the proforma. A sterile speculum examination was performed on admission in every patient to confirm the diagnosis of PROM. Digital examination was not done unless the patient was in labour. Amniotic fluid was collected for microscopic examination and bacteriological culture. Patients were selected for the study using the inclusion and exclusion criteria and informed consent was taken for participation in this study. Ultrasonographic examination was done to assess the amniotic fluid volume, fetal parameters, to identify the presenting part and to rule out major fetal anomalies, multiple gestation and placenta previa. Blood samples were collected from the study population at the time of admission for complete haemogram, C-reactive protein. These patients were managed conservatively with two doses of corticosteroid Betamethasone 12mg IM $24 \mathrm{hrs}$ apart to enhance fetal lung maturity. After the initial baseline workup subjects were randomised into three groups. The randomisation into the groups was done according to computer generated numbers. Group 1 received Ampicillin 1gm IV 6 hrly for 48 hrs followed by amoxicillin $500 \mathrm{mg}$ orally 8 hrly for 5 days. Group 2 received oral erythromycin $250 \mathrm{mg} 8$ hrly for 7 days. Group 3 received Ampicillin 1gm IV 6 hourly + Metronidazole $500 \mathrm{mg}$ IV 8 hourly for 48 hrs followed by amoxicillin 500mg orally 8 hrly for 5 days. Strict maternal and fetal monitoring was done in labour room for 48 hours. Those not in labour, with no signs and symptoms of clinical chorioamnionitis and a reassuring fetal status were monitored in the maternity ward which included a weekly high vaginal swabs and estimation of total leucocyte count twice a week. Indications for discontinuing expectant management and delivering the patients were those with clinical evidence of chorioamnionitis, non-reassuring fetal heart rate pattern, severe oligohydramnios, more than 34 weeks of gestation with continuous leaking per vaginum. The study group was followed for the following 3 outcomes.

* Those who continued with pregnancy were observed for fetal growth and wellbeing.

* Those who went into spontaneous labour were followed with close monitoring of labour. Progress of labour, mode of delivery and fetal parameters including sex, birth weight, Apgar score at 1 minute and 5 minutes were recorded.

* Those with indications for induction of labour as per indications were induced as per the standard hospital protocol either with PGE2 gel or oxytocics if required. Mode of delivery and fetal parameters were recorded. 
Caesarean section was done for maternal and fetal indications including failed induction. Any operative/abdominal delivery was recorded.

Mothers were followed for evidence of sepsis and babies for neonatal sepsis, NICU admissions, CNS morbidity in terms of abnormal cerebral ultrasonography. Placental membranes were sent for culture sensitivity. Histopathological examination of placenta and umbilical cord was done to identify histologic chorioamnionitis and funisitis.

The results of the study were evaluated on the basis of maternal outcome like prolongation of latency period, development of clinical chorioamnionitis, post-partum sepsis and post-partum haemorrhage, microbiological evidence in case of positive high vaginal swab results and evidence of histological chorioamnionitis in placental membranes and funisitis in cord and fetal outcome which included gestational age at delivery and birth weight, admission to nursery/NICU, presence of neonatal sepsis evidenced by positive sepsis screen, positive blood culture, radiological evidence of pneumonia, CNS morbidity in terms of abnormal cerebral ultrasonography prior to discharge. The results were then compiled and analyzed. The statistical analysis was done by using latest version of SPSS software. The results were expressed as mean \pm standard deviation. Student $t$-test and ANOVA were used to find the difference between the three groups.

\section{Results:-}

The demographic profile as depicted in Table I in all the three groups was comparable. Majority of the women were predominantly in the age between 20 to 30 years $(89.4 \%)$. The mean age of the women in the study population was $23.9 \pm 3.2$ years ranging from $19-32$ years. More than half of the women were multigravidas (54\%). The socioeconomic status of most of the women $(86.7 \%)$ was low. The clinical profile of womenin all the groups had no difference. The rupture of membranes in increasing order of gestation was $18 \%, 28.7 \%$ and $53.3 \%$ at $28-30,30$ 32 and 32-34 weeks respectively. Almost three-fourths of the women presented with leaking of more than 12 hours duration, the average duration of leaking in all three groups was $14.85 \pm 4.93$ hours ranged from 1-24 hours. Though the difference in the mean duration of leaking in all three groups was not significant ( $\mathrm{p}=0.507)$, almost all women $(96.3 \%)$ presented with oligohydramnios. The liquor volume as estimated in USG was very low in majority of the women. The mean AFI in all the groups was $4.47 \pm 2.42 \mathrm{~cm}$ with values ranging from nil to $9.2 \mathrm{~cm}$. A significantly higher percentage of women in Group 2 who received erythromycin had AFI less than 5 compared to those who received ampicillin (Group1) and ampicillin plus metronidazole (Group3) (80\% vs. 56\% and 62\%).

Table I:-Comparison of Demographic Profile in all three groups

\begin{tabular}{|c|c|c|c|c|c|}
\hline \multirow[t]{2}{*}{ Variables } & \multirow[t]{2}{*}{ Category } & \multicolumn{3}{|c|}{ No of women $(n=150)$} & \multirow{2}{*}{$\begin{array}{l}\text { Total } \\
\text { (n) }(\%)\end{array}$} \\
\hline & & Group1 (n) (\%) & Group2 (n) (\%) & Group3 (n) (\%) & \\
\hline \multirow[t]{4}{*}{ Age(years) } & $<20$ & $2(4)$ & $3(6)$ & $3(6)$ & $8(5.3)$ \\
\hline & $20-25$ & $29(58)$ & $28(56)$ & $24(48)$ & $81(54)$ \\
\hline & $25-30$ & $16(32)$ & $17(34)$ & $20(40)$ & $53(35.4)$ \\
\hline & $>30$ & $3(6)$ & $2(4)$ & $3(6)$ & $8(5.3)$ \\
\hline $\begin{array}{l}\text { Mean } \pm \text { SD } \\
\text { (in years) } \\
\text { Range(years) }\end{array}$ & \multicolumn{5}{|c|}{$\begin{array}{l}23.99 \pm 3.22 \\
19-32\end{array}$} \\
\hline \multirow[t]{4}{*}{ Obstetric Status } & 1 & $23(46)$ & $21(42)$ & $25(50)$ & $69(46.0)$ \\
\hline & 2 & $11(22)$ & $13(26)$ & $11(22)$ & $35(23.3)$ \\
\hline & 3 & $10(20)$ & $9(18)$ & $10(20)$ & $29(19.3)$ \\
\hline & $\geq 4$ & $6(12)$ & $7(14)$ & $4(8)$ & $17(11.4)$ \\
\hline \multirow[t]{2}{*}{ Socio-economic Status } & Middle & $10(20)$ & $12(24)$ & $8(16)$ & $30(13.3)$ \\
\hline & Lower & $40(80)$ & $38(76)$ & $42(84)$ & $120(86.7)$ \\
\hline \multirow[t]{2}{*}{ Booking Status } & Booked & $28(56)$ & $25(50)$ & $31(62)$ & $84(56)$ \\
\hline & Unbooked & $22(44)$ & $25(50)$ & $19(38)$ & $66(44)$ \\
\hline
\end{tabular}


Table II:- Comparison of Clinical Profile on admission in all three groups

\begin{tabular}{|l|l|l|l|l|l|}
\hline Variable & Category & \multicolumn{2}{l|}{ No of women(n=150) } & $\begin{array}{l}\text { Total } \\
(\mathrm{n})(\%)\end{array}$ \\
\cline { 3 - 6 } & & Group1 (n) $(\%)$ & $\begin{array}{l}\text { Group2 } \\
(\mathrm{n})(\%)\end{array}$ & $\begin{array}{l}\text { Group3 } \\
(\mathrm{n})(\%)\end{array}$ & \\
\hline \multirow{2}{*}{$\begin{array}{l}\text { Gestational age at } \\
\text { admission (in weeks ) }\end{array}$} & $28-30$ & $8(16)$ & $8(16)$ & $11(22)$ & $27(18)$ \\
\cline { 2 - 6 } & $30-32$ & $16(32)$ & $15(30)$ & $12(24)$ & $43(28.7)$ \\
\cline { 2 - 6 } & $32-34$ & $26(52)$ & $27(54)$ & $27(54)$ & $80(53.3)$ \\
\hline \multirow{2}{*}{$\begin{array}{l}\text { Duration of leaking } \\
\text { (hours) }\end{array}$} & $<6$ & $3(6)$ & $0(0)$ & $2(4)$ & $5(3.3)$ \\
\cline { 2 - 6 } & $6-12$ & $14(28)$ & $12(24)$ & $13(26)$ & $39(26)$ \\
\cline { 2 - 6 } & $>12$ & $33(66)$ & $38(76)$ & $35(70)$ & $106(70.7)$ \\
\hline \multirow{2}{*}{ AFI at time of admission(cm) } & $<5$ & $28(56)$ & $40(80)$ & $31(62)$ & $100(66.6)$ \\
\cline { 2 - 6 } & $5-8$ & $21(42)$ & $10(20)$ & $15(30)$ & $46(30.7)$ \\
\cline { 2 - 6 } & $>8$ & $1(2)$ & $0(0)$ & $4(8)$ & $4(2.7)$ \\
\hline
\end{tabular}

Table IIIa shows the effect of antibiotic prophylaxis on prolongation of pregnancy. The mean gest age at delivery in all three groups was $32.91 \pm 1.44,32.66 \pm 1.36$ and $32.96 \pm 1.64$ weeks respectively with mean duration from admission to delivery being $8.92 \pm 7.13,6.18 \pm 6.11$ and $9.34 \pm 9.17$ days.

The latent period between rupture of membranes and delivery was significantly longer in the women who received Ampicillin (Group 1) compared to women who received oral erythromycin (8.92 \pm 7.12 vs $6.18 \pm 6.11$ days, $\mathrm{p}=0.005$ ). Similarly women in Group 3 who received combination of Inj. Ampicillin with metronidazole also showed a significant prolongation of latency compared to women who received oral erythromycin $(9.34 \pm 9.17$ days vs. $6.18 \pm 6.11$ days; $\mathrm{p}=0.048)$. However the difference in the latent period between Ampicillin and Ampicillin with metronidazole group was found to be non-significant ( $8.92 \pm 7.12$ vs. $9.34 \pm 9.17$ days; $p=0.482)$. (Table IIIb)

Table IIIa:-Comparison of Pregnancy outcome in all the three groups.

\begin{tabular}{|c|c|c|c|c|}
\hline \multirow[t]{2}{*}{ Variable } & \multicolumn{3}{|c|}{ No of women $(n=150)$} & \multirow[t]{2}{*}{ p-value } \\
\hline & Group1 $(n=50)$ & $\begin{array}{l}\text { Group2 } \\
(\mathrm{n}=50)\end{array}$ & $\begin{array}{l}\text { Group3 } \\
(\mathrm{n}=50)\end{array}$ & \\
\hline $\begin{array}{l}\text { Mean Gestational age at admission } \\
\text { (in weeks ) }\end{array}$ & $31.64 \pm 1.57$ & $31.71 \pm 1.64$ & $31.59 \pm 1.73$ & \multirow[t]{3}{*}{0.017} \\
\hline $\begin{array}{l}\text { Mean Gestational age at delivery (in } \\
\text { weeks ) }\end{array}$ & $32.91 \pm 1.44$ & $32.66 \pm 1.36$ & $32.96 \pm 1.64$ & \\
\hline $\begin{array}{l}\text { Mean Interval from admission to } \\
\text { delivery (latent period )(in days) }\end{array}$ & $8.92 \pm 7.13$ & $6.18 \pm 6.11$ & $9.34 \pm 9.17$ & \\
\hline
\end{tabular}

Table IIIb:-Comparison of latency period in all the three groups.

\begin{tabular}{|l|l|l|}
\hline \multicolumn{2}{|l|}{ Latency period (days) (Mean \pm SD) } & p-value \\
\hline Group 1 & Group 2 & $\mathbf{0 . 0 0 5}$ \\
$8.92 \pm 7.13$ & $6.18 \pm 6.11$ & \\
\hline Group 2 & Group 3 & $\mathbf{0 . 0 4 8}$ \\
$6.18 \pm 6.11$ & $9.34 \pm 9.17$ & \\
\hline Group 1 & Group 3 & 0.482 \\
$8.92 \pm 7.13$ & $9.34 \pm 9.17$ & \\
\hline
\end{tabular}

The comparison of maternal and neonatal outcome between the three groups revealed (table IV) development of clinical chorioamnionitis in 3 women who received erythromycin (Group 2) with none in the other two groups. The difference was highly significant $(\mathrm{p}=0.047)$. Mild PPH occurred in only one patient in group 1 . None of the women in the study population developed puerperal sepsis post delivery. There was no serious complication noted in the population.

The neonatal outcome was favourable with no significant difference in all the three groups. On comparison of neonatal outcome in terms of mean birth weight, live births, still births, NICU admissions, neonatal sepsis, CNS morbidity, and neonatal deaths between the three groups, the difference was not statistically significant. 
Table IV:-Comparison of maternal \& neonatal outcome between the three groups.

\begin{tabular}{|c|c|c|c|c|c|c|}
\hline & \multirow[t]{2}{*}{ Outcome } & \multicolumn{3}{|l|}{ Group } & \multirow{2}{*}{$\begin{array}{l}\text { Total } \\
(\mathrm{n})(\%)\end{array}$} & \multirow[t]{2}{*}{$\mathrm{p}$-value } \\
\hline & & $\begin{array}{l}\text { Group } 1 \\
(\mathrm{n})(\%)\end{array}$ & $\begin{array}{l}\text { Group } 2 \\
(\mathrm{n})(\%)\end{array}$ & $\begin{array}{l}\text { Group } 3 \\
(\mathrm{n})(\%)\end{array}$ & & \\
\hline \multirow[t]{3}{*}{ Maternal } & Chorioamnionitis & $0(0)$ & $3(6)$ & $0(0)$ & $3(2)$ & 0.047 \\
\hline & $\begin{array}{l}\text { Post-partum } \\
\text { haemorrhage }\end{array}$ & $1(2)$ & $0(0)$ & $0(0)$ & $1(0.7)$ & NS \\
\hline & Puerperal sepsis & $0(0)$ & $0(0)$ & $0(0)$ & $0(0)$ & NS \\
\hline \multirow[t]{7}{*}{ Neonatal } & Live births & 50 & 50 & 50 & 150 & NS \\
\hline & Still births & 0 & 0 & 0 & 0 & NS \\
\hline & $\begin{array}{l}\text { Birth weight }(\mathrm{Kg}) \\
(\text { Mean } \pm \text { SD })\end{array}$ & $1.75 \pm 0.30$ & $1.74 \pm 0.29$ & $1.84 \pm 0.32$ & & NS \\
\hline & NICU admissions & 23 & 25 & 20 & 68 & NS \\
\hline & Neonatal sepsis & 0 & 1 & 0 & 1 & NS \\
\hline & CNS morbidity & 1 & 3 & 3 & 7 & NS \\
\hline & Neonatal deaths & 1 & 1 & 0 & 2 & NS \\
\hline
\end{tabular}

\section{Discussion:-}

PROM is an important obstetric problem that places both mother and child at the risk of infection and the fetus at risk of preterm delivery and complications of prematurity. Hence the factors affecting its incidence and finding its best management options is of prime importance. In the present study, a high preponderance of preterm PROM in the age group of 20-30 years can be explained by the fact that this age group (20-30 years) is highly fertile with more reproductive potential. This was similar to the finding byVargani et al [22] who reported the mean maternal age of pPROM in his study was 29.1 years. Several factors can be a predisposing factor for onset of rupture of membrane. The present study observed that most of the women were multiparous. Multiparity is a risk factor for membrane rupture due to diminished membrane strength. Similar results were reported by Spinato et al [23] in 1987 and by Ekwo et al[24] in 1993. Multiparity is a risk factor for pPROM due to longstanding infection, previous trauma to cervix and patulous os. The socio-economic status of women affects the incidence of pPROM due to increased risk of vaginal infections in women of lower socio-economic status. Also tobacco smoking and nutritional deficiencies of copper and ascorbic acid which predispose to PPROM are more prevalent in lower socio-economic status. In the present study, 86.7\% (130/150) women with pPROM belonged to lower class according to modified Kuppuswamy's socioeconomic status scale. This is in accordance with the study done by swatipandey et al[25].

Maximum number of cases were seen between 33-34 weeks of gestation and lowest number of cases were seen between 28-29 weeks of gestation with increasing incidence of pPROM as gestational age increases. This is consistent with the study by Mercer et al(1999)[26] in which the incidences of spontaneous preterm delivery before $28,30,32,35$, and 37 weeks' gestation were $0.8 \%, 1.1 \%, 1.9 \%, 5.1 \%$, and $11.9 \%$ respectively and the incidence of pPROM increased with increase in gestational age. The risk of chorioamnionitis also depends on the gestational age. At early gestational ages, the latency period is longer with high risk of chorioamnionitis. However at late gestational ages, the latency period is shorter with low risk of chorioamnionitis. Similarly, the duration of leaking also has a direct correlation to the infectious morbidity of mother and fetus. In the present study, the mean duration of leaking in group 1, group 2 and group 3 was $14.56 \pm 5.72$ hours, $15.42 \pm 4.89$ hours and $14.58 \pm 4.09$ hours respectively. Although the mean duration of leaking was higher in the erythromycin treated group, however the difference was not statistically significant. In the present study most of the women presented with decreased liquor volume due to prolonged and continuous leak with concomitant decreased AFI (less than 5). The less the amniotic fluid volume the more likely labour can set in. Women in the erythromycin had significantly less AFI compared to the other two groups. Hence, the latency in women who received erythromycin can be affected by decreased AFI. Latency period refers to time interval between rupture of membranes and delivery. Literature reports that the administration of antibiotics in pPROM seems to be of benefit in prolonging the latency period thus delaying the progression to preterm birth and reducing complications of prematurity like RDS and IVH. Numerous studies done in the past including those by John Owen [14], Almeida et al[17], Mercer BM et al[19]revealed significant prolongation in the latency period in women receiving antibiotics as compared to placebo. In the present study when the effect of antibiotics was compared with respect to latency period, the administration of IV ampicillin followed by oral amoxicillin and IV ampicillin + IV metronidazole was associated with significant prolongation of latency period and 
reduced risk of chorioamnionitis. Though the effectiveness of ampicillin in pPROM has been reported by various studies in past, till now only one study has been done to show the effect of metronidazole in patients with pPROM(1996, J. Svare[18]). However no difference was found between the antibiotic group and placebo group in terms of prolongation of latency. This could be due to small sample size and non-blinded nature of the study which may have introduced bias in patient management. The mean latency period in erythromycin group was $6.18 \pm 6.11$ days and the incidence of chorioamnionitis was higher in the erythromycin group. This difference may be seen due to variation in the antibiotic sensitivity pattern of bacteria responsible for causing pPROM in women in the study group, presence of severe oligohydramnios in erythromycin group or due to oral route of administration of this drug. No studies to the best of our knowledge have been done in the past to compare the effects of these three regimens against each other. Though the present study has shown a beneficial effect of ampicillin or ampicillin+ metronidazole over erythromycin in terms of latency period and chorioamnionitis, it failed to reveal a statistically significant impact on infant morbidity and mortality. This may be due to smaller number of cases in each group.

\section{Conclusion:-}

Prophylactic antibiotic treatment with either ampicillin in single or in combination with metronidazole (ampi+ metronidazole) was associated with prolongation of the duration of pregnancy following preterm PROM and favorable maternal outcome (no clinical chorioamnionitis) compared to oral erythromycin .However it failed to reveal a statistically significant impact on infant morbidity and mortality in terms of birth weight, NICU admissions, neonatal sepsis, abnormal cerebral ultrasound prior to discharge. The findings herein justify further studies to determine the optimal anti-microbial regimen and duration of treatment in patients with preterm PROM.

\section{References:-}

1. ACOG Committee on Practice Bulletins-Obstetrics. Premature Rupture of Membranes. (ACOG Practice Bulletin No. 1). Obstetric Gynecol. 1998; 143:625-26.

2. ACOG Committee on Practice Bulletins-Obstetrics. Clinical management guidelines for obstetriciangynecologists. (ACOG Practice Bulletin No. 80: premature rupture of membranes). Obstetric Gynecol. 2007; 109:1007-19.

3. Kenyon S, Boulvain M, Neilson JP. Antibiotics for preterm rupture of membranes. Cochrane Database of systemic reviews 2003, Issue 2. Art No. : CD001058. DOI:10.1002/14651858.CD001058.

4. Lebherz TB, Hellman LP, Madding Ret al. Double Blind study of premature rupture of membranes. Am J Obstet Gynecol. 1963;87:218-25.

5. Amon E, Lewis SV, Sibaj BM, Villar MA, Arheart KL. Ampicillin prophylaxis in preterm premature rupture of membranes: a prospective randomized study. Am J Obstet Gynecol. 1988;159(3):539-43.

6. Morales WJ, Angel JL, O'Brien WF, Knuppel RA. Use of ampicillin and corticosteroids in premature rupture of membranes: a randomized study. Obstet Gynecol. 1989;73(5):721-6.

7. Fortunato SJ, Welt SI, Eggleston M, Cole J, Bryant EC, Dodson MG. Prolongation of the latency period in preterm premature rupture of the membranes using prophylactic antibiotics and tocolysis. $\mathrm{J}$ Perinatol. 1990;10(3):252-6.

8. Johnston MM, Sanchez-Ramos L, Vaughan AJ, Todd MW, Benrubi GI. Antibiotic therapy in preterm premature rupture of membranes: a randomized, prospective, double-blind trial. Am J Obstet Gynecol. 1990;163(3):743-7.

9. McGregor JA, French JI, Seo K. Antimicrobial therapy in preterm premature rupture of membranes: results of a prospective, double-blind, placebo-controlled trial of erythromycin. Am J Obstet Gynecol. 1991;165:632-40.

10. Mercer BM, Moretti ML, Prevost RR, Sibai BM. Erythromycin therapy in preterm premature rupture of the membranes: a prospective, randomized trial of 220 patients. Am J Obstet Gynecol. 1992;166:794-802.

11. Christmas JT, Cox SM, Andrew W, Dax J, Leveno KJ, Gilstrap LC. Expectant management of preterm ruptured membranes: effects of antimicrobial therapy. Obstet Gynecol. 1992;80:759-62.

12. Kurki T, Hallman M, Zilliacus R, Teramo K, Ylikorkala O. Premature rupture of the membranes; effect of penicillin prophylaxis and long term outcome of the children. Am J Perinatol.1992;9:11-6.

13. Lockwood CJ, Costigan K, Ghidini A, Wein R, Chien D, Brown BL. Double-blind, placebo-controlled trial of piperacillin prophylaxis in preterm membrane rupture.Am J Obstet Gynecol. 1993;169:970-6.

14. Owen J, Groome LJ, Hauth JC. Randomized trial of prophylactic therapy after preterm amnion rupture. Am J Obstet Gynecol. 1993;169(4):976-81.

15. Ernst JM, Givner LB. A prospective, randomized, placebo-controlled trial of penicillin in preterm premature rupture of membranes. Am J Obstet Gynecol. 1994;170(2):516-21. 
16. Grable IA, Garcia PM, Perry D, Socol ML. Group B streptococcus and preterm premature rupture of membranes: a randomized, double-blind clinical trial of antepartum ampicillin. Am J Obstet Gynecol. 1996;175:1036-42.

17. Almeida L, Schmauch A, Bergstrom S. A randomized study on the impact of per oral amoxicillin in women with prelabour rupture of membranes preterm. GynecolObstet Invest.1996;41:82-4.

18. Svare J. Preterm delivery and subclinical uro-genital infection [thesis]. Denmark: Department of Obstetrics and GynaecologyRigshospitalet, University of Copenhagen, 1997.

19. Mercer B. The NICHD-MFMU antibiotic treatment of PPROM study: evaluation of factors associated with successful outcome. Am J Obstet Gynecol. 1997;176(2):S8.

20. Mercer B, Miodovnik M, Thurnau G, Goldenberg R, Das A, Merenstein G et al. A multicentre randomized controlled trial of antibiotic therapy vs. placebo therapy after preterm premature rupture of the membranes. Am J Obstet Gynecol. 1996;174(2):304.

21. Mercer BM, Miodovnik M, Thurnau GR, Goldenberg RL, Das AF, Ramsey RD et al. Antibiotic therapy for reduction of infant morbidity after preterm premature rupture of the membranes. 1997;278:989-95.

22. Vergani P, Chidini A, Locatelli A, Cavallone M, Ciaria S, Capellini A et al. Risk factors for pulmonary hypoplasia in second trimester premature rupture of membranes. Am J Obstet Gynecol. 1994;170:1359-64.

23. Spinnato JA, Shaver DC, Brag EM, Lipshitz J. Preterm premature rupture of membranes with fetal pulmonary maturity present: a prospective study. Obst Gynecol. 1987;69:196-201.

24. Ekwo-Gosselink CA, Moawada. Previous pregnancy comes and subsequent risk of preterm rupture of amniotic soc membranes. Br J Obstet Gynecol. 1993;100(6):534-41.

25. Pandey S, Devi A, Bandi S. Maternal and fetal outcome in cases of PROM. Obstet and Gynaecol.1980; 136:796-804.

26. Mercer BM et al. The preterm prediction study: effect of gestational age and cause of preterm birth on subsequent obstetric outcome. Am J Obstet Gynecol. 1999; 181:1216-21. 